\title{
The Dogs of the Dow Theory - Is It Valid?
}

\author{
Doh-Khul Kim ${ }^{1}$ \\ ${ }^{1}$ Department of Accounting and Finance, North Central College, Naperville, IL, USA \\ Correspondence: Doh-Khul Kim, Department of Accounting and Finance, 30 N. Brainard St., North Central \\ College, Naperville, IL 60540, USA. Tel: 630-637-5243. E-mail: dkim@ noctrl.edu
}

Received: February 24, 2019

Accepted: March 30, 2019

Online Published: April 8, 2019

doi:10.5539/ijef.v11n5p43

URL: https://doi.org/10.5539/ijef.v11n5p43

\begin{abstract}
The Dogs of the Dow theory has been a popular tool in the financial market. But while the theory is simple, there have been mixed findings on its validity. Using U.S. data from 2000 through 2017, this paper identifies how consistently an investment strategy that follows the Dogs of the Dow theory outperforms the average market. The results show that the theory has not worked well in the recent U.S. market when trading costs and taxes are included. Rather, holding an equally weighted investment of all firms is more likely to outperform the Dow Jones Industrial Average index and the Dogs of the Dow strategy in the long term.
\end{abstract}

Keywords: Dogs of Dow theory, dividend yield, rates of returns, top-10 firms

\section{Introduction}

One simple strategy that is popular in investment is the Dogs of the Dow (DoD) theory. It is a simple dividend-yield based investment, which was initially introduced by J. Slatter in the Wall Street Journal in 1988. The theory became widely known to the public through the work of O'Higgins and Downes (1992), and many others. The DoD strategy proposes to invest in the top 10-highest dividend-yield stocks out of 30 Dow Jones Industrial Average (DJIA) index firms at the beginning of the year and sell the stocks at the end of the year. If we follow the strategy and rebalance our portfolio at the beginning of each year, the average rates of returns (RoRs) will exceed the bench mark indices, such as DJIA and S\&P 500.

The logicality of the DoD theory can be shown in two ways. First, a high dividend yield is achieved when a firm pays high dividends. In general, high dividends positively affect the stock price, and it is commonly accepted in the financial market. High dividends are taken as a positive sign of the firm's future due to the existence of asymmetric information between the firm's managers and the public. Second, a high dividend yield is achieved with a low(er) stock price, which will lead to a low Price-Earnings ratio. Such a low stock price with low P-E ratio can create an undervaluation of a company, which can provide a greater potential for capital gains.

Many researchers have worked on the validity of the DoD theory, but with a lack of a strong consensus. Using data in Taiwan and Thai stock markets, respectively, Yan et al. (2015) and Tissayakorn et al. (2013) showed that the DoD strategy earned higher returns than the benchmark in each country. Soomro and Haroon (2015) also confirmed that the DoD strategy outperformed the benchmark in the Pakistani market, with some limitations. Chong and Luk (2010) also showed that the DoD strategy works well for the blue-chip stocks of the Hang Seng Index in Hong Kong.

However, Hirschey (2000) showed no robust evidence of outperformance by the DoD strategy. Even though his work on the U.S. market (1961-1998) showed years of outperformance by the DoD, the strategy was in line with the DJIA after adjusting for taxes and rebalancing costs. He argued that no abnormal returns are possible if the costs of taxes and rebalancing are included, which ultimately supports the efficient-market hypothesis. Using data from some Latin American countries, Da Silva (2001) found no statistically meaningful evidence for the validity of the DoD theory. Even though the DoD strategy produced higher risk-adjusted returns than the index in most of the countries under investigation, such abnormal returns were not statistically strong enough across the countries.

McQueen et al. (1997) showed that the DoD strategy earned higher returns than the DJIA only on an absolute basis (nominal returns). The strategy did not outperform the U.S. market index when the trading costs of buying/selling and taxes were included. Domian et al. (1998) showed that all the abnormal returns of high-dividend DJIA stocks were related to the market- overreaction hypothesis, which does not support the DoD 
theory. Rather, they proposed that the best possible strategy in investment is to buy and hold a well-diversified portfolio.

The main purpose of this research is to update the validity of the DoD theory. To this end, this paper uses the data from the U.S. market. Furthermore, the RoRs of the top-10 firms are compared to both equally weighted investments of all firms and the DJIA index, as the bench mark index is price weighted. And this is the main difference from the existing research, as many of them have considered the validity of the DoD theory by comparing top-10 firms' returns to the bench mark index only. In addition, this paper shows further comparisons for top-five firms, which is another difference.

\section{Data and Analysis}

The annual data, obtained from Bloomberg, span from 2000 to 2017. The Dow Jones Industrial Average (DJIA) index firms during the period are shown in Table 1. There have been several changes in the components, and 42 firms have appeared in the index during the period.

Table 1. Dow jones industrial average component firms: 2000-2017

\begin{tabular}{|c|c|c|c|c|c|c|c|}
\hline $2000-03$ & 2004 & 2005-07 & 2008 & 2009-11 & 2012 & 2013-14 & $2015-17$ \\
\hline AA & AA & AA & AA & AA & $\mathrm{AA}$ & AXP & AXP \\
\hline AXP & AXP & AXP & AXP & AXP & AXP & $\mathrm{T}$ & AAPL \\
\hline $\mathrm{T}$ & AIG & $\mathrm{T}$ & $\mathrm{T}$ & $\mathrm{T}$ & $\mathrm{T}$ & BA & BA \\
\hline BA & $\mathrm{T}$ & BA & BA & BA & BA & BAC & CAT \\
\hline CAT & BA & CAT & BAC & BAC & BAC & CAT & CVX \\
\hline $\mathrm{C}$ & CAT & $\mathrm{C}$ & CAT & CAT & CAT & CVX & $\mathrm{CSCO}$ \\
\hline DWDP & $\mathrm{C}$ & DWDP & CVX & CVX & CVX & $\mathrm{CSCO}$ & DWDP \\
\hline XOM & DWDP & XOM & $\mathrm{C}$ & CSCO & CSCO & DWDP & XOM \\
\hline GE & XOM & GE & DWDP & DWDP & DWDP & XOM & GE \\
\hline $\mathrm{GM}^{*}$ & GE & GM & XOM & XOM & XOM & GE & GS \\
\hline HD & GM & HD & GE & GE & GE & GS & HD \\
\hline $\mathrm{HON}$ & $\mathrm{HD}$ & $\mathrm{HON}$ & GM & HD & HD & HD & IBM \\
\hline HPQ & $\mathrm{HON}$ & HPQ & $\mathrm{HD}$ & HPQ & HPQ & IBM & INTC \\
\hline IBM & HPQ & IBM & HPQ & IBM & IBM & INTC & JNJ \\
\hline INTC & IBM & INTC & IBM & INTC & INTC & JNJ & JPM \\
\hline IP & INTC & JNJ & INTC & JNJ & JNJ & JPM & $\mathrm{KO}$ \\
\hline JNJ & IP & JPM & JNJ & JPM & JPM & $\mathrm{KO}$ & $\mathrm{MCD}$ \\
\hline JPM & JNJ & $\mathrm{KO}$ & JPM & $\mathrm{KHC}$ & $\mathrm{KO}$ & MCD & MMM \\
\hline $\mathrm{KO}$ & JPM & KODK & $\mathrm{KHC}^{*}$ & $\mathrm{KO}$ & MCD & MMM & MRK \\
\hline $\mathrm{KODK}^{*}$ & $\mathrm{KO}$ & MCD & $\mathrm{KO}$ & MCD & MMM & MRK & MSFT \\
\hline MCD & MCD & MMM & MCD & MMM & MRK & MSFT & NKE \\
\hline MMM & MMM & MO & MMM & MRK & MSFT & PG & PG \\
\hline MO & MO & MRK & MRK & MSFT & PG & PFE & PFE \\
\hline MRK & MRK & MSFT & MSFT & PG & PFE & TRV & TRV \\
\hline MSFT & MSFT & PG & PG & PFE & TRV & UNH & UNH \\
\hline PG & PG & PFE & PFE & TRV & UNH & UTX & UTX \\
\hline UTX & UTX & UTX & UTX & UTX & UTX & $\mathrm{VZ}$ & $\mathrm{VZ}$ \\
\hline WMT & $\mathbf{V Z}$ & $\mathrm{vZ}$ & $\mathrm{vZ}$ & $\mathrm{VZ}$ & $\mathrm{VZ}$ & $\mathbf{V}$ & $\mathrm{V}$ \\
\hline DIS & WMT & WMT & WMT & WMT & WMT & WMT & WMT \\
\hline $\mathrm{SBC}^{* *}$ & DIS & DIS & DIS & DIS & DIS & DIS & DIS \\
\hline
\end{tabular}

Note. The components are shown in stock codes, and newly added firms are shown in bold. * indicates KODK, GM and KHC whose data are not included here due to lack of full availability. ** is for SBC Communications that was acquired by AT\&T (T) later.

Most of the firms pay dividends four times a year with steady growth rates during the period, and the average dividend yield during the period is around $2.74 \%$. The average dividend yield of all Dow firms each year is shown in Table 2. 
Table 2. Average annual dividend yield of all dow index firms (\%)

\begin{tabular}{cc}
\hline & Average dividend yield \\
\hline 2000 & 2.47 \\
2001 & 2.09 \\
2002 & 2.45 \\
2003 & 3.13 \\
2004 & 2.65 \\
2005 & 3.10 \\
2006 & 2.90 \\
2007 & 2.77 \\
2008 & 2.69 \\
2009 & 4.32 \\
2010 & 2.60 \\
2011 & 2.44 \\
2012 & 2.72 \\
2013 & 2.68 \\
2014 & 2.42 \\
2015 & 2.44 \\
2016 & 2.74 \\
2017 & 2.62 \\
Average & 2.74 \\
\hline
\end{tabular}

The dividend yield for each firm is obtained by dividing the previous year's dividend payments by the last day closing stock price of the previous year.

$\mathrm{DY}_{\mathrm{t}}=\mathrm{TD}_{\mathrm{t}-1} / \mathrm{SP}_{\mathrm{t}-1}$

Where $\mathrm{DY}_{\mathrm{t}}=$ Dividend yield at the start of current year

$$
\begin{aligned}
& \mathrm{TD}_{\mathrm{t}-1}=\text { Total dividend payments of previous year } \\
& \mathrm{SP}_{\mathrm{t}-1}=\text { Closing stock price at the end of previous year }
\end{aligned}
$$

One simple way to identify how well the Dogs of the Dow (DoD) theory works is to find how many firms are cross-ranked in both top-10 yields and the rates of returns (RoRs). Table 3 shows the number of firms that are cross-ranked across the two in the same year with dividend payments included and excluded, respectively. Dividend payments are included in the rates of returns for the comparison between the top-10 highest yield firms and equally weighted investments of all firms. In addition, the rates of returns are also obtained with dividend payments excluded for the comparison between the top-10 firms and the bench mark index returns, DJIA, as the index itself does not include the dividend.

The maximum number is 10 , which is possible when all top-10 highest dividend yield firms are ranked in top-10 highest rates of returns. When the number is zero, it indicates that no top-10 dividend yield firms are ranked in the top-10 returns, which implies that the returns are completely unrelated to the dividend yield. As Table 3 shows, the number of firms range between one and six with no consistency during the period. In addition, the average numbers of cross-ranked firms during the entire period are 3.56 and 3.22 out of 10, respectively. Hence, from this simple research, the DoD theory is not robust enough during the period.

Table 3. Number of cross-ranked firms in Top-10 dividend yields and Top-10 RoRs in same year: with and without dividend payments included for RoRs

\begin{tabular}{lcc}
\hline & \multicolumn{2}{c}{ Number of firms } \\
\cline { 2 - 3 } 2000 & with dividend payments & without dividend payments \\
2001 & 5 & 5 \\
2002 & 3 & 3 \\
2003 & 4 & 4 \\
2004 & 5 & 4 \\
2005 & 5 & 3 \\
2006 & 2 & 2 \\
\hline
\end{tabular}




\begin{tabular}{ccc}
\hline 2007 & 3 & 2 \\
2008 & 3 & 3 \\
2009 & 2 & 2 \\
2010 & 6 & 6 \\
2011 & 6 & 6 \\
2012 & 3 & 2 \\
2013 & 1 & 1 \\
2014 & 2 & 2 \\
2015 & 3 & 3 \\
2016 & 5 & 5 \\
2017 & 1 & 1 \\
Average & 3.56 & 3.22 \\
\hline
\end{tabular}

Table 4 shows the annual RoRs of all firms (equally weighted investment), top-10 and top five firms, along with percent of change in the DJIA index. The annual RoRs for both top-10 and top-five firms include the dividend payments, which are also properly adjusted for any stock splits during the period. The RoRs range between $-31.07 \%$ (2008) and 36.79\% (2003) for all firms, $-38.65 \%$ (2008) and $45.76 \%$ (2003) for the top-10 firms, and $-45.09 \%$ (2008) and $40.67 \%$ (2003) for the top-five firms, whereas the percent of change in the DJIA range between $-33.84 \%$ (2008) and $26.50 \%$ (2013). The losses are the greatest for all four in 2008, which is the first year of the Great Recession.

Table 4. Annual Rates of Returns (RoRs) (\%): With dividend payments included

\begin{tabular}{ccccc}
\hline & $\begin{array}{c}\text { All Dow firms (equally } \\
\text { weighted investments) }\end{array}$ & $\begin{array}{c}\text { \% change in Dow index } \\
\text { (price weighted) }\end{array}$ & $\begin{array}{c}\text { Top-10 dividend-yield } \\
\text { firms }\end{array}$ & $\begin{array}{c}\text { Top-five dividend-yield } \\
\text { firms }\end{array}$ \\
\hline 2000 & 0.30 & -6.18 & 13.14 & 26.63 \\
2001 & -4.78 & -7.09 & -2.79 & 3.90 \\
2002 & -17.08 & -16.76 & -12.43 & -9.76 \\
2003 & 36.79 & 25.32 & 45.76 & 40.67 \\
2004 & 8.86 & 3.16 & 11.45 & 18.19 \\
2005 & 4.17 & -0.61 & 5.61 & 5.12 \\
2006 & 19.37 & 16.29 & 24.25 & 36.10 \\
2007 & 11.06 & 6.43 & 8.49 & 14.09 \\
2008 & -31.07 & -33.84 & -38.65 & -45.09 \\
2009 & 29.28 & 18.82 & 23.95 & 28.83 \\
2010 & 11.07 & 11.02 & 15.59 & 11.94 \\
2011 & 3.13 & 5.53 & 17.61 & 14.67 \\
2012 & 14.62 & 7.26 & 6.51 & 4.62 \\
2013 & 31.94 & 26.50 & 26.07 & 25.22 \\
2014 & 11.20 & 7.52 & 10.75 & 12.13 \\
2015 & 3.23 & -2.23 & 3.42 & 10.31 \\
2016 & 14.61 & 13.41 & 20.06 & 28.25 \\
2017 & 25.28 & 25.08 & 17.90 & 14.78 \\
\hline
\end{tabular}

It is found that the RoRs of top-10 firms are substantially higher than those of all firms and the index from 2000 through 2006. In other words, the DoD investment strategy works well and outperforms the equally weighted investments and the price-weighted DJIA index. However, since 2006 (through 2017), the RoRs of top-10 firms are higher than both equally weighted investments and the Dow index only four times. Hence, the DoD strategy does not work well, and it is hard to validate the DoD theory over the next 12 years (since 2006). Thus, during the entire period (2000-2017) the results are mixed, and the DoD strategy does not consistently outperform the equally weighted investments and the Dow index. The DoD strategy itself does not consistently produce any higher returns than the average market; the result is in line with the efficient-market hypothesis.

Looking at the top-five firms, the RoRs outperform those of all firms and the index 13 times during the 18 year-period. Thus, the DoD strategy works better for top-five firms than top-10 firms. Nonetheless, the DoD strategy for top-five firms does not robustly outperform the equally weighted investments and the Dow index during the period. 
Table 5 shows both arithmetic and geometric average RoRs during the period. The arithmetic (simple annual average) and geometric (true annual) averages of top-10 firms are $10.93 \%$ and $9.37 \%$, respectively, and these are slightly higher than those of equally weighted investments of all firms (9.55\% and 8.22\%). However, as the DoD strategy requires that we rebalance our portfolio at the end (or start) of each year, we need to consider the transaction costs and the corresponding taxes on profits. Hence, if we adjust the RoRs after including all of the trading costs and taxes, there is no meaningful difference between the RoRs of the top-10 firms and equally weighted investments. In other words, the DoD strategy does not outperform the equally weighted investments during the period due to the existence of the transaction costs and taxes, which can be called a 'rebalancing fee.' Even though the costs and taxes are not measurable exactly, we can assume they are around 20 to 25\% (out of total profits) each year.

Table 5. Average annual growth rate for 2000-2017 (\%): With dividend payments included

\begin{tabular}{ccc}
\hline & Arithmetic average & Geometric average \\
\hline Equally weighted investment & 9.55 & 8.22 \\
Dow index & 5.53 & 4.34 \\
Top-10 firms & 10.93 & 9.37 \\
Top-five firms & 13.37 & 11.40 \\
\hline
\end{tabular}

The RoRs of top-five firms are $13.37 \%$ and $11.40 \%$, respectively, which are also higher than those of equally weighted investments. However, if we include costs and taxes, it is hard to say that the DoD strategy works well for even the top-five firms in the long term. The DoD strategy does not robustly outperform the equally weighted investments in the long term when the rebalancing fee is considered.

Comparing to the percentage change of Dow index, the RoRs of the top-10 and -five firms are more than twice as high as the index change. However, such higher returns mainly stem from the dividend payments. The Dow index change does not include the dividend payments, unlike the top-10 and -five firms. Hence, for better comparisons, the RoRs are re-estimated with the dividend payments excluded for both top-10 and -five firms, respectively. Table 6 shows the annual RoRs of all firms, top-10 and top-five firms, along with the index change with all the dividend payments excluded. Due to the exclusion of dividend payments, the RoRs in Table 6 are all lower than those in Table 4.

Table 6. Annual Rates of Returns (RoR) (\%): With dividend payments excluded

\begin{tabular}{ccccc}
\hline & $\begin{array}{c}\text { All Dow firms (equally } \\
\text { weighted investments) }\end{array}$ & $\begin{array}{c}\text { \% change in Dow index } \\
\text { (price weighted) }\end{array}$ & $\begin{array}{c}\text { Top-10 dividend-yield } \\
\text { firms }\end{array}$ & $\begin{array}{c}\text { Top-five dividend-yield } \\
\text { firms }\end{array}$ \\
\hline 2000 & -2.40 & -6.18 & 7.35 & 16.98 \\
2001 & -7.04 & -7.09 & -7.25 & -2.85 \\
2002 & -19.67 & -16.76 & -17.36 & -17.13 \\
2003 & 33.34 & 25.32 & 39.40 & 31.15 \\
2004 & 5.62 & 3.16 & 6.15 & 10.38 \\
2005 & 1.18 & -0.61 & 0.27 & -2.30 \\
2006 & 16.16 & 16.29 & 18.60 & 28.20 \\
2007 & 8.06 & 6.43 & 3.54 & 7.50 \\
2008 & -33.80 & -33.84 & -42.67 & -49.79 \\
2009 & 26.18 & 18.82 & 20.34 & 25.87 \\
2010 & 8.40 & 11.02 & 11.54 & 7.24 \\
2011 & 0.30 & 5.53 & 13.55 & 9.86 \\
2012 & 11.55 & 7.26 & 2.24 & -0.17 \\
2013 & 28.93 & 26.50 & 21.96 & 20.67 \\
2014 & 8.51 & 7.52 & 7.07 & 8.12 \\
2015 & 0.56 & -2.23 & -0.18 & 6.40 \\
2016 & 11.67 & 13.41 & 16.11 & 23.84 \\
2017 & 22.49 & 25.08 & 14.32 & 10.89 \\
\hline
\end{tabular}

As Table 7 shows, the arithmetic and geometric averages for top-10 firms are $6.39 \%$ and $4.78 \%$, respectively. And these are lower than those of all firms (6.67\% and 5.32\%). In addition, the RoRs of top-10 firms are now 
slightly higher than the Dow index (5.53 and 4.34\%). If we include the trading costs and taxes, there is no meaningful difference between the RoRs of top-10 firms and the percent of change in the index. Hence, the DoD strategy for the top-10 firms does not outperform the index (average market) during the period. In addition, using the geometric average, the average return for top-five firms is only around $1 \%$ higher than the index. Hence, the DoD strategy for even the top-five firms does not outperform the average market during the period if costs and taxes are included. Once again, the results only support the efficient-market hypothesis and the findings by Hirschey (2000).

Table 7. Average annual growth rate for 2000-2017 (\%): With dividend payments excluded

\begin{tabular}{ccc}
\hline & Arithmetic average & Geometric average \\
\hline Equally weighted investment & 6.67 & 5.32 \\
Dow index & 5.53 & 4.34 \\
Top-10 firms & 6.39 & 4.78 \\
Top-five firms & 7.49 & 5.45 \\
\hline
\end{tabular}

The holding period returns and standard deviations are shown in Table $8 \mathrm{a}$ and $8 \mathrm{~b}$ for dividend payments included and excluded. With dividend payments included, the returns are more than twice as high as those of dividend payments excluded. However, the standard deviations are slightly higher for dividend payments included. Hence, this shows the importance of the dividend payments in long-term investments when there are both rising and declining markets. There is a substantial difference between the two RoRs, whereas the fluctuations are slightly higher. Most of the Dow-component firms are used to pay the dividends on a regular basis (four times a year) with steady growth rates.

Table 8a. Holding period return and standard deviation with dividend payments included (\%)

\begin{tabular}{ccc}
\hline & Holding period return & Standard deviation \\
\hline Equally weighted investment & 314.34 & 16.80 \\
Dow index & 115 & 15.44 \\
Top-10 firms & 401.27 & 17.65 \\
Top-five firms & 597.81 & 19.20 \\
\hline
\end{tabular}

Table 8b. Holding period return and standard deviation with dividend payments excluded (\%)

\begin{tabular}{ccc}
\hline & Holding period return & Standard deviation \\
\hline Equally weighted investment & 154.16 & 16.62 \\
Dow index & 115 & 15.44 \\
Top-10 firms & 131.74 & 17.45 \\
Top-five firms & 160.05 & 18.84 \\
\hline
\end{tabular}

\section{Conclusions}

Even though the Dogs of the Dow (DoD) theory is a logical strategy in long-term investments, this paper shows that it does not work well in the U.S. market. Using the data of DJIA companies since 2000, this paper shows that the RoRs of top-10 highest dividend-yield firms are not meaningfully higher than those of equally weighted investments for both dividend payments included and excluded. After adjusting for trading costs and taxes, there is no substantial difference between the RoRs of the top-10 firms and equally weighted investments of all firms. In addition, when we excluded the dividend payment from the RoRs, the returns of top-10 firms are not statistically higher than the Dow index after controlling for transaction costs and taxes.

Narrowing the research to the top-five highest dividend-yield firms, the results are no different from those of top-10 firms. The RoRs of top-five firms (with dividend payments included) are higher than those of equally weighted investments of all firms (by 3.18\%). However, if we include all the costs and taxes, it is hard to confirm that the returns of top-five firms outperform the equally weighted investments overall. In addition, when we exclude the dividend payments, the RoRs of top-five firms are not statistically higher than the Dow index after controlling for costs and taxes.

Hence, with dividend payments included, the returns of top-10 and top-five firms do not outperform those of equally weighted investments of all Dow firms after adjusting for costs and taxes. In addition, with dividend 
payments excluded, the returns of top-10 and top-five firms are slightly higher than the Dow index. Thus, if we consider costs and taxes, the returns of both top-10 and top-five firms do not outperform the index, either. The DoD strategy does not work in the U.S. in the long term, even though there were some consecutive years (2000 2006) when the strategy worked well. Rather, investing equal amounts across the 30 index firms and holding for the long term is more likely to outperform the Dow index (price weighted) by almost $1 \%$ each year. This is in line with the findings of Domian et al. (1998). Hence, investing in funds such as the Exchange Traded Funds (ETF) that invest equal amounts across the Dow firms will be a better investment than those that simply follow the market index of the DJIA.

\section{References}

Chong, T. T., \& Kin, K. L. (2010). Does the 'Dogs of the Dow' Strategy Work Better in Blue Chips? Applied Economics Letters, 17(12), 1173-75. https://doi.org/10.1080/17446540902845495

Da Silva, A. L. C. (2001). Empirical Tests of the Dogs of the Dow Strategy in Latin American Stock Markets. International Review of Financial Analysis, 10(2), 187-99. https://doi.org/10.1016/S1057-5219(01)00047-3

Domian, D. L., Louton, D. A., \& Mossman, C. E. (1998). The Rise and Fall of the 'Dogs of the Dow'. Financial Services Review, 7, 145-59. https://doi.org/10.1016/S1057-0810(99)00007-4

Fama, E. F. (1998). Market Efficiency, Long-term Returns and Behavioral Finance. Journal of Financial Economics, 49, 283-306. https://doi.org/10.1016/S0304-405X(98)00026-9

Hirschey, M. (2000). The 'Dogs of the Dow' Myth. The Financial Review, 35(2), 1-15. https://doi.org/10.1111/j.1540-6288.2000.tb01411.x

McQueen, G., Shields, K., \& Thorley, S. (1997). Does the Dow 10 Investment Strategy Beat the Dow Statistically and Economically? Financial Analysts Journal, 53, 66-72. https://dx.doi.org/10.2469/faj.v53.n4.2101

O’Higgins, M., \& Downes, J. (1991). Beating the Dow. New York: Harper Perennial.

Slatter, J. (1988). Study of Industrial Averages Finds Stocks with High Dividends Are Big Winners. Wall Street Journal (Eastern Edition), August 11.

Soomro, N., \& Haroon, M. A. (2015). Comparison of Dog's of the Dow Strategy. Universal Journal of Management, 3(3), 127-30. DOI: 10.13189/ujm.2015.03030

Tissayakorn, K., Song, Y., Qiu, M., \& Akagi, F. (2013). A Study on Effectiveness of the 'Dogs of the Dow' Strategy for the Thai Stock Investment. International Journal of Innovation, Management and Technology, 4(2), 277-80. https://doi.org/10.7763/IJIMT.2013.V4.406

Yan, H., Song, Y., Qiu, M., \& Akagi, F. (2015). An Empirical Analysis of the Dogs of the Dow Strategy for the Taiwan Stock Market. Journal of Economics, Business and Management, 3(4), 435-39. https://dx.doi.org/10.7763/JOEBM.2015.V3.224

\section{Copyrights}

Copyright for this article is retained by the author(s), with first publication rights granted to the journal.

This is an open-access article distributed under the terms and conditions of the Creative Commons Attribution license (http://creativecommons.org/licenses/by/4.0/). 